Review Article

\title{
A Pathophysiological Insight into Sepsis and Its Correlation with Postmortem Diagnosis
}

\author{
C. Pomara, I. Riezzo, S. Bello, D. De Carlo, M. Neri, and E. Turillazzi \\ Department of Clinical and Experimental Medicine, Section of Forensic Pathology, Ospedale Colonnello D’Avanzo, \\ University of Foggia, Viale degli Aviatori 1, 71100 Foggia, Italy
}

Correspondence should be addressed to E. Turillazzi; emanuela_turillazzi@inwind.it

Received 23 December 2015; Revised 21 March 2016; Accepted 10 April 2016

Academic Editor: Dianne Cooper

Copyright (C) 2016 C. Pomara et al. This is an open access article distributed under the Creative Commons Attribution License, which permits unrestricted use, distribution, and reproduction in any medium, provided the original work is properly cited.

Background. Sepsis is among the leading causes of death worldwide and is the focus of a great deal of attention from policymakers and caregivers. However, sepsis poses significant challenges from a clinical point of view regarding its early detection and the best organization of sepsis care. Furthermore, we do not yet have reliable tools for measuring the incidence of sepsis. Methods based on analyses of insurance claims are unreliable, and postmortem diagnosis is still challenging since autopsy findings are often nonspecific. Aim. The objective of this review is to assess the state of our knowledge of the molecular and biohumoral mechanisms of sepsis and to correlate them with our postmortem diagnosis ability. Conclusion. The diagnosis of sepsis-related deaths is an illustrative example of the reciprocal value of autopsy both for clinicians and for pathologists. A complete methodological approach, integrating clinical data by means of autopsy and histological and laboratory findings aiming to identify and demonstrate the host response to infectious insults, is mandatory to illuminate the exact cause of death. This would help clinicians to compare pre- and postmortem findings and to reliably measure the incidence of sepsis.

\section{Introduction}

Sepsis can be defined as a syndrome of dysregulated inflammation caused by the failure of infection control and containment mechanisms. It should be considered a major public health problem since it affects millions of people worldwide each year, with an incidence which is dramatically increasing [1]. It accounts for most deaths in critically ill patients [2-4]. The hospital mortality of patients with sepsis ranges from 28.3 to $41.1 \%$ in North America and Europe $[5,6]$.

Consequently, considerable attention is dedicated to sepsis by policymakers and caregivers. However, these efforts are tempered by several limitations. First of all, difficulty in defining sepsis still exists due to the emerging biological insights and reported variation in epidemiology. Recently the Third International Consensus Definitions Task Force defined sepsis as "life-threatening organ dysfunction due to a dysregulated host response to infection" $[7,8]$; however the performance of clinical criteria for this sepsis definition is unknown [7]. Furthermore, sepsis poses heavy challenges from a clinical point of view regarding its early detection and the best organization of sepsis care [6,9]. Finally, we do not yet have reliable tools for measuring the incidence of sepsis. Methods based on analyses of insurance claim data using sepsis-specific codes or separate codes for infection and organ dysfunction are unreliable in informing or measuring the effects of policy changes [1], and the postmortem diagnosis of sepsis is still challenging as the results of postmortem investigations often show a relative paucity of significant macroscopic and histopathological findings [10, 11]. Apart from the possibility of demonstrating infected sites in the internal organs (i.e., septicopyaemic abscess), the inflammatory organ changes observed at autopsy are mediated by the endogenous inflammatory mediators that are neither specific nor sensitive with regard to sepsis [11]. These can also be demonstrated in different clinical conditions going along with systemic inflammatory response syndrome (SIRS) or prolonged ischemia [11]. Furthermore, the presence of a pathogen in the blood or tissues does not necessarily indicate that the complex syndrome of sepsis has occurred [12]. These issues are further demonstrated by the discrepancies existing between clinical and postmortem diagnosis of sepsis [13-15]. 
Despite the fact that the latter is still a diagnosis of exclusion, sepsis is an intriguing field of interest in autopsy practice, and the diagnosis of sepsis-related deaths is an illustrative example of the reciprocal value of autopsy both for clinicians and for pathologists. Upon studying these deaths, the pathologist needs to approach the complex pathophysiological mechanisms underlying sepsis. This may lead in turn to an increased understanding of the pathogenic hypotheses and to the accuracy of existing diagnostic tools to be checked [16]. Autopsies should still serve as a very important part of quality control in clinical diagnosis and treatment of sepsis $[17,18]$. Last but not least, the issue of the diagnostic reliability of fatal sepsis is even more pivotal. One important area which has seen a rising number of clinical negligence claims comprises healthcare-associated infections and sepsis [19].

The objective of this review is to assess the state of our knowledge of the molecular and biohumoral mechanisms of sepsis and to correlate them with our postmortem diagnosis ability.

\section{The Inflammatory Response}

The septic response is an extremely complex chain of events involving inflammatory and anti-inflammatory processes, humoral and cellular reactions, and circulatory changes. When an infectious insult occurs, it initiates a series of events, resulting in the release of inflammation mediators which involves both a local reaction and a systemic response and which, finally, could impact on organs function [20].

Sepsis triggers the production of a diverse array of cytokines that are proinflammatory and anti-inflammatory $[21,22]$. Cytokines are low molecular weight compounds which are considered potent positive and negative regulators of inflammation. Some cytokines possess proinflammatory effects such as tumour necrosis factor- (TNF-) alpha, interleukin- (IL-) 1, and interleukin-8, while others have anti-inflammatory effects including IL-10 and IL-1 receptor antagonist, and some are supposed to act as pro- and antiinflammatory IL-6 as an example [23].

Proinflammatory cytokines trigger a beneficial response, such as increased local coagulation, limited tissue damage, and elimination of the pathogen. Overwhelming production of these proinflammatory cytokines, however, can be very dangerous in that excessive cytokines destroy the normal regulation of the immune response and induce pathological inflammatory disorders, such as capillary leakage, tissue injury, and organ failure. Similarly, the anti-inflammatory cytokines play a critical role in regulating overall immune response, in establishing homeostasis, and in checking the effects of the proinflammatory ones in order to solve inflammation and heal tissue. Therefore, their dysregulation can also trigger pathogenesis [24], since it has been shown that an intense anti-inflammatory response may induce a state of immunosuppression in patients with sepsis [25]. When a state of anti-inflammatory predominance occurs, monocytes are deactivated. This results in reduced antigen presentation and decreased production of proinflammatory cytokines, leading to pathogen persistence and further fuelling the inflammatory process $[21,22,25]$. A tightly regulated balance in the cytokine network, which comprises pro- and antiinflammatory cytokines, is crucial for eliminating invading pathogens on the one hand and restricting excessive, tissuedamaging inflammation on the other [26].

In brief, when an infectious insult occurs, pattern recognition receptors (PRRs), which are expressed on epithelial barriers as well as on resident immune cells such as dendritic cells and macrophages, detect invading microorganisms. A specific family of PRRs named toll-like receptors (TLRs) recognizes conserved macromolecular motifs from microorganisms, called pathogen-associated molecular patterns (PAMPs). The stimulation of TLRs or the nucleotide oligomerization domain NOD-like receptor (NLR) family of intracellular PRRs results in the triggering of downstream signalling cascades. Depending on the particular receptor engaged, this process leads to the activation of a transcriptional response programme that includes nuclear factor $\kappa \mathrm{B}(\mathrm{NF}-\kappa \mathrm{B})$, followed by the production and secretion of cytokines, chemokines, and nitric oxide [21, 22]. Cytokines usually bind their specific receptors, induce signalling pathways, and thus regulate immune responses and other cell functions [24].

Therefore, different types of cells, tissues/organs, or protein/other molecules may function as effectors, modulating the immune response through various pro- or anti-inflammatory mediators. Resident macrophages and polymorphonuclear cells (PMCs) initiate the primary host response to the invading microorganisms. They are responsible for the primary phagocytosis and subsequent activation and recruitment of granulocytes and monocytes. Leukostasis of neutrophils (the so-called leucocyte sticking) in the liver sinusoids, in the pulmonary vessels, and so forth is the common histological counterpart of this phenomenon [11]. Proliferation of astrocytes and microglial cells is a common postmortem histological finding in septic patients. However, it is highly nonspecific as it may reflect several kinds of insults, including ischemia [11].

Endothelial cells (ECs) activation occurs during sepsis. The interaction between ECs and leukocytes, a hallmark of the inflammatory process, comprises adhesive and migratory molecular events including low-affinity transient and reversible rolling adhesions, integrin-dependent firm adhesive interactions, and migratory events of the leukocytes through the endothelium and, finally, in the interstitial space [27, 28]. A variety of chemical mediators secreted from inflamed tissue and the entire process of leukocyteendothelial cell adhesion are regulated by the sequential activation of different families of adhesion molecules that are expressed on the surface of leukocytes and ECs. Lectin-like adhesion glycoproteins, selectins, mediate leukocyte rolling. The firm adhesion and subsequent transendothelial migration of leukocytes are mediated by the interaction of integrins expressed by leukocytes with immunoglobulin-like adhesion molecules on ECs, for example, intercellular cell adhesion molecules (ICAM) 1-5, vascular cell adhesion molecule-1 (VCAM-1), and the junctional adhesion molecules (JAMs), which are expressed on endothelial and other cells [29, 30]. Recently, EC-active molecules (i.e., the angiopoietin pathway, Ang-2, soluble fms-like tyrosine kinase-1) have been 
proposed to correlate significantly with organ dysfunction and mortality in patients with sepsis [31, 32].

Sepsis is also associated with robust activation of the complement system, as demonstrated by the presence of complement activation products (C3a, C5a, and C5b-9) in the plasma [33]. C3a and C5a anaphylatoxins are small cleavage products of $\mathrm{C} 3$ and $\mathrm{C} 5$ and possess proinflammatory activities. C5a especially reacts with its receptors on phagocytes (neutrophils, macrophages) and on a variety of organs to trigger numerous biological effects. These include increasing vascular permeability and inducing smooth muscle contraction, inducing chemotaxis of PMCs, monocytes, and other cell types $[34,35]$. In experimental studies on animal models (rats or mice with cecal ligation and puncture, CLP), both rabbit polyclonal neutralizing antibodies and mouse monoclonal antibodies that neutralized C5a were highly effective in attenuating the parameters of sepsis (clinical symptoms, evidence of multiorgan failure, MOF, consumptive coagulopathy, innate immune functions, apoptosis, etc.), resulting in greatly improved survival $[36,37]$. The effects of C5a contribute to immunoparalysis, MOF, the apoptosis of thymocytes and adrenal medullary cells, and imbalances in the coagulation system [38]. In addition, C5a is involved in the development of septic cardiomyopathy and severe left ventricular dysfunction [39]. At autopsy, the left ventricle is often dilated and the ventricular walls have a flaccid appearance [11].

Other products derived from activation of the complement system play an important role in sepsis, such as $\mathrm{C} 3 \mathrm{~b}$ (from C3), which is a key opsonisation factor that reacts with phagocytes receptors to favour internalization of bacteria and their subsequent elimination. The membrane attack complex (C5b-9) causes lysis of Gram-negative bacteria [38].

Finally, sepsis also affects other biological systems, such as the coagulation system and the autonomic nervous system [39]. In the clinical setting of sepsis, dysregulation of the coagulation cascade results in major complications. The extent of activation of the coagulation cascade during sepsis can range from an insignificant level to the occurrence of disseminated intravascular coagulation (DIC). When DIC occurs, at autopsy various degree of haemorrhage can be observed on the skin, on mucocutaneous surfaces and serous membranes, and, finally, in parenchymal organs $[10,11]$. Increasing evidence points to an extensive cross talk between inflammation and coagulation, in which the protease activated cell receptors play an important role (Figure 1).

\section{The Concept of "Compartmentalization" of the Inflammatory Response in Sepsis}

A fundamental step in the comprehension of sepsis pathophysiology is to appreciate that the inflammatory response varies from one compartment to another, and not all compartments behave similarly [40]. Chinnaiyan et al. supported this concept by studying gene expression in different tissues in CLP model of sepsis in rats. They showed that the sepsis response elicited gene expression profiles that were either organ specific, common to more than one organ, or distinctly opposite in some organs [41].
Each organ has a distinctive molecular response to systemic inflammation. Several experimental pieces of data confirm this observation. For example, neutrophil sequestration in lung and liver resulted differently regulated by chemokines in a murine experimental model of peritonitis [42]. After injection of LPS (lipopolysaccharide) in a mice model, NF- $\kappa$ B activation in liver was mediated through TNF and IL-1 receptor-dependent pathways, but, in the lung, LPS induced NF- $\kappa$ B activation was largely independent of these receptors [43]. Although data are still missing in humans, mouse alveolar macrophages do not produce IL-10 [44], do not express TLR9, and are thus insensitive to bacterial DNA [45] and fail to produce IFN- $\beta$ in response to TLR4 and TLR3 agonists [46], thus demonstrating that, in this animal model, alveolar macrophages behave differently to other types of macrophages.

Through the bloodstream a strict cross talk exists between the different organs and compartments. Both pro- and antiinflammatory mediators are present concomitantly in the bloodstream, evoking different responses in the various organs. The latter, in turn, respond through the local production of different mediators and the activation of different cellular types [40]. Most tissues contribute to the release of inflammatory mediators and there is local activation of intracellular signalling pathways [40].

This concept is of paramount clinical importance as the various organs may respond differently to therapeutic strategies. On the other hand, upon approaching sepsisrelated deaths, pathologists must keep in mind that tissue injury can be initiated remotely from an insult in a faraway site and that all organs and compartments may be involved (Figure 2).

Different organs and systems are interconnected via humoral and biochemical interactions and are clustered into functional modules sharing many common pathophysiological mechanisms. Diagnostic postmortem strategies based on the measurement of compartmentalized mediators may prove useful as a diagnostic strategy $[47,48]$.

\section{Microcirculation and Microvesicles}

Sepsis is a disease of microcirculation [49]. Nuclear vacuolization, cytoplasmic swelling and protrusion, cytoplasmic fragmentation, and various degrees of endothelial detachment from its basement membrane have been demonstrated during sepsis $[50,51]$. Endothelial physical disruption leads to an extravascular leak of protein-rich oedema and polymorphonuclear cells (PMNs) influx into organs. Furthermore, endothelial damage may induce leukocyte and platelet aggregation, as well as aggravation of coagulopathy, thus favouring impaired perfusion, tissue hypoxia, and subsequent organ dysfunction [51, 52].

Deleterious effects on the vascular function are mediated by increased synthesis of inflammatory cytokines and chemokines and increased expression of endothelial adhesion molecules [49-51]. Microvascular endothelial cells (MVECs) that are critical modulators of blood flow and microvascular function are principal targets of the systemic inflammation of sepsis [52]. 


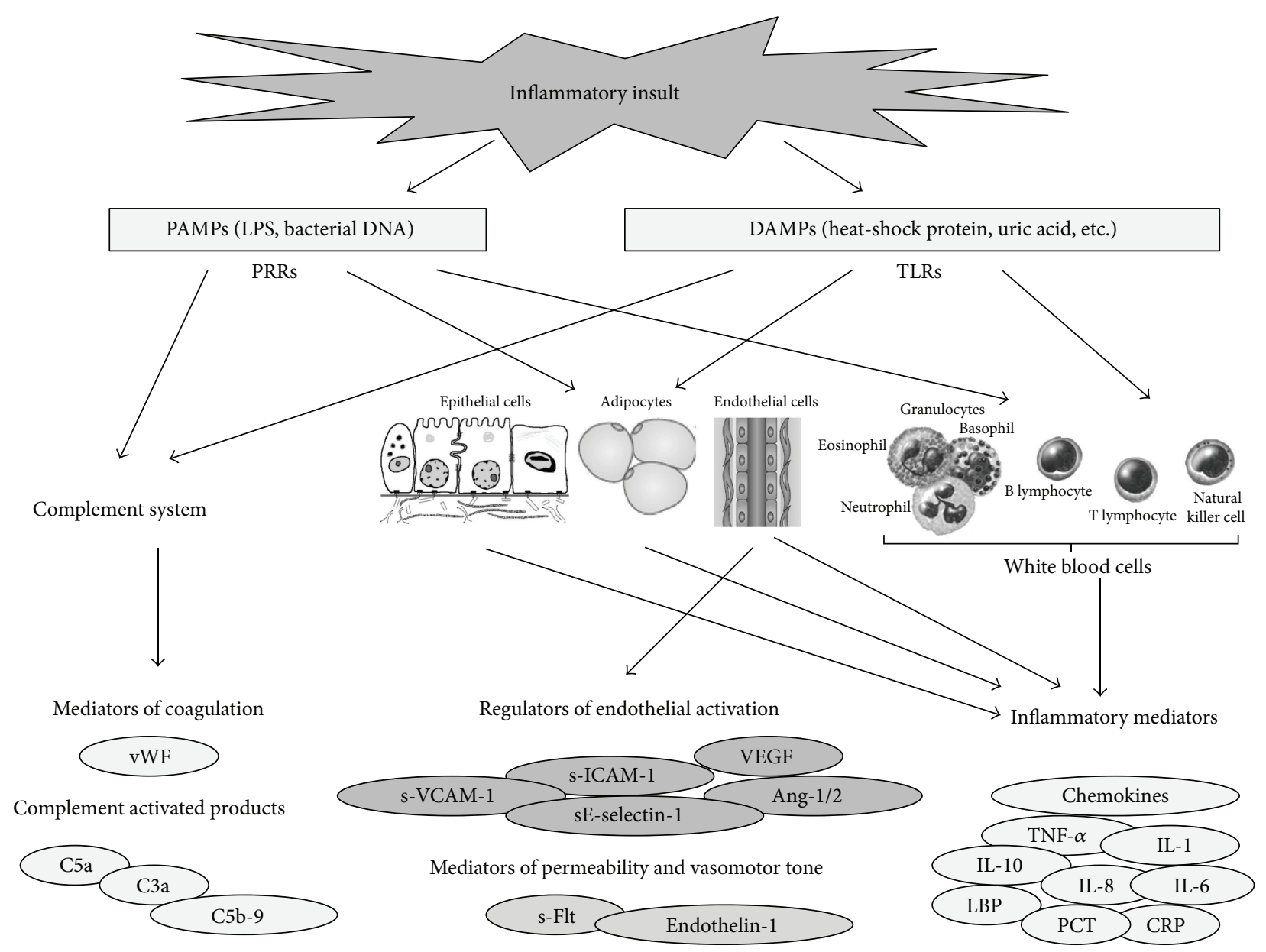

FIGURE 1: Schematic of events associated with major mediators of cytokine cascade on initiation of sepsis. The release of a large amount of pathogen and damage associated molecular patterns (PAMPs and DAMPs) from invading microorganisms and/or damaged host tissue, respectively, results in the overstimulation of pattern-recognition receptors (PRRs) of immune cells. This process activates an inflammatory cascade in which large amounts of cytokines are released into the body. Macrophages and endothelial cells are then hyperactivated by the unusually large quantity of circulating cytokines. The activation of macrophages and endothelial cells results in the release of more cytokines, exacerbating the inflammatory response. The profound proinflammatory response is counteracted by certain anti-inflammatory cytokines, including IL-10, transforming growth factor- $\beta$ (TGF- $\beta$ ), and IL-4, which attempt to restore immunological equilibrium.

Microvasculature dysfunction in sepsis is almost ubiquitous. Pulmonary MVECs injury and barrier dysfunction result in the leak of protein-rich fluid and circulating neutrophils into the pulmonary interstitium and alveolar spaces [52-54]. Recently it has been demonstrated that septic pulmonary microvascular barrier dysfunction is associated with significant pulmonary MVECs death, which is largely apoptotic [52]. Experimental observations provide proof that septic acute kidney injury (AKI) can occur in the setting of renal hyperaemia and that ischemia is not necessarily present. Nonhemodynamic mechanisms of cell injury are likely to be at work, due to a combination of immunologic, toxic, and inflammatory factors that may affect the microvasculature and the tubular cells [55-58]. There is evidence that adhesion molecule activation, both on the renal endothelium and on epithelial cells, leads to enhanced leukocyte adhesion, followed by the influx of activated leukocytes into the renal interstitium [57]. Finally, renal mitochondrial dysfunction has been demonstrated in CLP murine model of sepsis leading to a decrease in renal complexes $I$ and II/III respiration, MnSOD (manganese superoxide dismutase) activity, and ATP levels. This was associated with increased mitochondrial superoxide levels, impaired renal microcirculation, and impaired renal function [59]. Oxidant generation by the renal tubules and renal microvascular failure are early events, which lead to AKI [60-62]. Cerebral microcirculatory dysfunction has been demonstrated in various experimental models of sepsis [63], and it is thought to be one of the main pathophysiological mechanisms leading to brain damage also in humans [64]. Both endotoxin, or more accurately termed bacterial lipopolysaccharide (LPS), and proinflammatory cytokines induce the expression of CD40, VCAM-1 or ICAM1 , and E-selectin on human brain microvessel endothelial cells [65-69].

Finally, in recent years a growing body of evidence has been established regarding the role of microvesicles (MVs) 


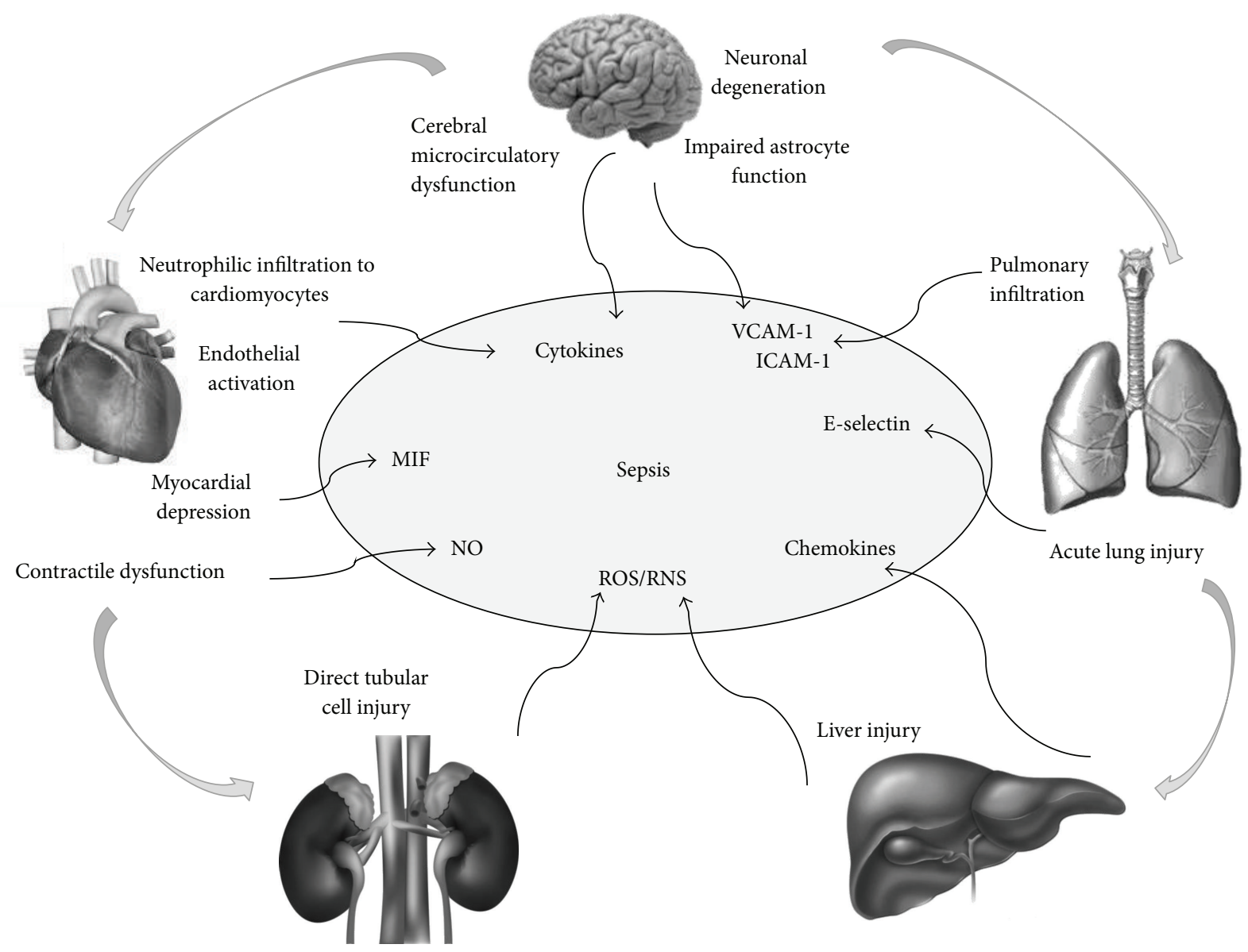

FIGURE 2: A schematic representing the involvement of different organs in sepsis. During sepsis large amounts of inflammatory mediators are found within the bloodstream. They can act on different organs and induce tissue injury that in turn will favour further production of inflammatory mediators. Cross talk between the different organs and tissues is further mediated by the local delivery of mediators that can amplify or limit the inflammatory response (MIF, macrophage migration inhibitory factor; NO, nitric oxide; ROS, reactive oxygen species; RNS, reactive nitrogen species; VCAM-1, vascular adhesion molecule-1; and ICAM-1, intercellular adhesion molecule-1).

in sepsis [70]. These extracellular vesicles are released in the extracellular environment through a membrane reorganization and blebbing process following cell activation or apoptosis. They constitute a storage pool of bioactive effectors with varied cellular origins and are able to act as intercellular messengers or effectors through multiple amplification and regulatory loops affecting vascular cells functions [71]. Thus, MVs contribute to the spread of inflammatory and prothrombotic vascular status. They may also affect smooth muscle tissue through adhesion molecules, activation of NF$\kappa \mathrm{B}$, and the expression of inducible nitric oxide synthase and cyclooxygenase-2, with an increase in nitric oxide and vasodilator prostanoids, leading to arterial hyporeactivity [72-74].

In recent years, the analysis of circulating-cell-derived MVs has become more defined and clinically more useful, and several groups suggest that it may enter mainstream clinical testing $[75,76]$. Endothelial-derived microvesicles are considered relevant biomarkers of septic shock-induced DIC and have been proposed as a significant diagnostic tool to evaluate early vascular injury [74]. An increase of platelet derived microvesicles has been demonstrated in the development of sepsis-related renal impairment [77] and in severe fungal sepsis [78]. Finally, MVs released from peripheral blood PMNs have a similar size and orientation but differ in protein composition and functional properties. These affect endothelial cells, platelets, monocytes, and macrophages. They also show antibacterial properties since they are capable of a significant reduction in bacterial growth (Figure 3) [7981].

\section{The Blood Compartment}

Blood compartment plays a key role in the inflammatory response. Waves of mediators with both anti- and proinflammatory properties are detectable in the plasma of septic patients. Many of these are considered reliable markers for in vita diagnosis of sepsis and some have been proposed also as biological markers of the severity of sepsis, but none alone is entirely specific for infection because they can be also detected in the absence of infection [82]. The future direction of research is most likely to focus on the use of 


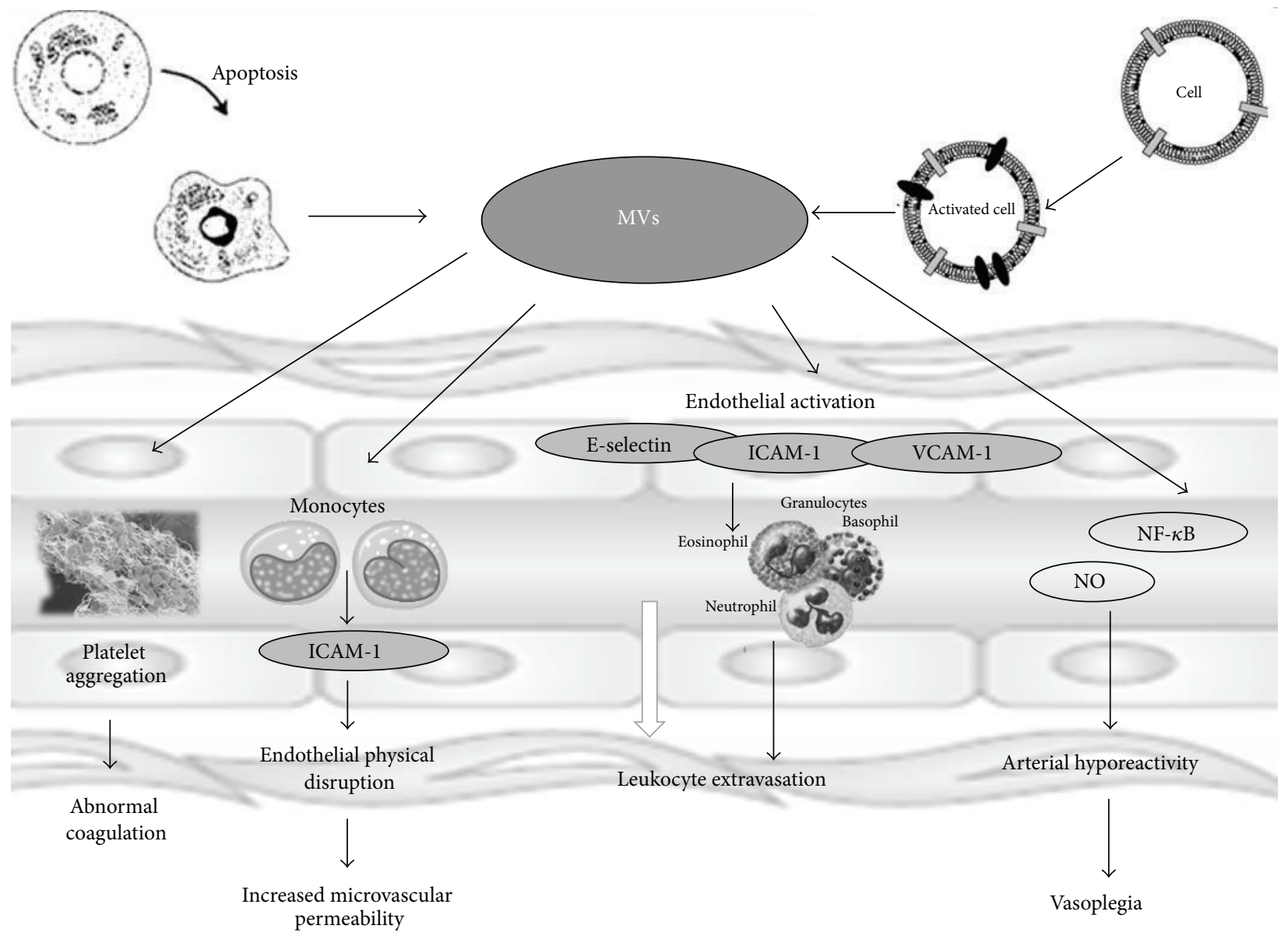

FIGURE 3: A schematic representing microvesicles (MVs) functions. MVs are released in the extracellular environment through a membrane reorganization and blebbing process following cell activation or apoptosis. They contribute to the spread of inflammatory and prothrombotic vascular status and they may affect smooth muscle tissue through adhesion molecules (E-selectin, ICAM, and VCAM) activation of nuclear factor $\kappa \mathrm{B}$ and the expression of inducible nitric oxide synthase and cyclooxygenase-2, with an increase in nitric oxide (NO) and vasodilator prostanoids, leading to arterial hyporeactivity.

panels or combinations of markers with clinical signs. Some biomarkers may also be useful for prognosis and guiding therapy [83-86]. However, nowadays the ideal biomarker, with high sensitivity and specificity and cost effectiveness and with definite cut-off ranges and time of blood sampling, is yet to be found [87].

As molecular and humoral mechanisms are thought to play a key part in the pathophysiology of sepsis, postmortem diagnostic strategies based on the concentration of such mediators have been investigated.

Many authors propose the detection of procalcitonin (PCT) as a useful and reliable marker of sepsis in routine autopsy investigations [88-91]. PCT, a prohormone composed of 116 amino acids, is the precursor of the calcium homoeostasis hormone calcitonin, which is found in thyroid $\mathrm{C}$ cells and pulmonary endocrine cells. Clinically relevant levels of PCT influence the immunologic responses that contribute to systemic inflammatory responses and septic shock. Many studies have indicated that PCT is an excellent marker of bacterial infection in patients with sepsis and its related conditions. Bode-Jänisch et al. outline that, at PCT levels $<2 \mathrm{ng} / \mathrm{mL}$, bacterial sepsis or septic shock can almost certainly be excluded as cause of death [89]. PCT levels $\geq 10 \mathrm{ng} / \mathrm{mL}$ can be detected occasionally in conditions other than sepsis. A final assessment should therefore take into account the PCT levels, autopsy results, and the histopathological and microbiological findings [91]. Other authors indicate high diagnostic accuracy for both lipopolysaccharidebinding protein (LBP) and PCT, considered individually and combined, in detecting sepsis-related outcomes in postmortem [92].

However, due to the detectability of high levels of PCT also in aseptic inflammation (i.e., chronic inflammatory and autoimmune conditions, myocardial infarction, etc.) [93103], a pressing need to identify additional biomarkers is evident [91].

As demonstrated by the studies mentioned above, much attention has been focused on cytokines and other mediators as diagnostic tools in many diseases and they certainly hold promise also for the discovery of reliable postmortem biomarkers of sepsis. 
Soluble interleukin-2 receptor (sIL-2R) and LBP seem to represent appropriate diagnostic tools for the postmortem diagnosis of sepsis [104]. Postmortem IL-6 and C-reactive protein (CRP) serum levels were investigated by Tsokos et al. in sepsis and nonseptic fatalities and both IL-6 and CRP serum concentrations seem to be suitable biochemical markers of sepsis [105]. However, since pathological conditions other than sepsis (trauma, burn injury, etc.) may be associated with elevated IL- 6 and/or CRP levels, the authors themselves warn about the need to rule out such conditions upon interpreting postmortem values of IL-6 and CRP [105].

Other biomarkers of potential relevance to sepsis/septic shock diagnostics have been proposed more recently.

Triggering receptor expressed on myeloid cells-1 (TREM1) is a recently discovered member of the immunoglobulin superfamily of receptors that is specifically expressed on the surfaces of neutrophils and monocytes and upregulated in bacterial sepsis. This is associated with a marked plasma elevation in the soluble form of this molecule (sTREM-1). Studies have indicated that sTREM-1 could be a valuable diagnostic biomarker for sepsis [106]. Palmiere et al. investigated sTREM-1 concentration in the serum of patients who died from sepsis and found that when individually considered, it did not provide better sensitivity and specificity than PCT in detecting sepsis. However, simultaneous assessment of PCT and sTREM-1 in postmortem serum could improve diagnostic accuracy [87]. Results from septic patients in intensive care units found that sTREM-1, PCT, and CRP levels indicate infection, while sTREM-1 and PCT levels predict prognosis. Moreover, sTREM-1 appears to be the best indicator for the diagnosis of sepsis and assessment of prognosis of blood culture-positive bacteremia [107].

Presepsin (sCD14-ST) is a soluble N-terminal fragment of protein CD14 which is released into circulation during monocyte activation on the recognition of LPS from infectious agents [108]; it shows promise for diagnostic and prognostic purposes in septic patients [109]. It has been investigated in sepsis-related death. The results show that even though increases in both PCT and sCD14-ST concentrations were observed in the control cases, coherent PCT and sCD14-ST results in cases with suspected sepsis allowed the diagnosis to be confirmed. Conversely, no relevant correlation was identified between postmortem serum and pericardial fluid sCD14-ST levels in either the septic or control groups [110].

Endocan (endothelial cell-specific molecule-1), a 50-kDa dermatan sulphate proteoglycan, expressed by endothelial cells in lung and kidney, can be detected at low levels in the serum of healthy subjects. Increased concentrations were described in patients with sepsis, severe sepsis, and septic shock compared to healthy individuals, with serum concentrations related to the severity of illness [111]. Palmiere and Augsburger found that postmortem serum endocan concentrations were significantly higher in sepsis fatal cases, with values ranging from $0.519 \mathrm{ng} / \mathrm{mL}$ to $6.756 \mathrm{ng} / \mathrm{mL}$, while, in most patients of the control group, endocan was undetectable. The authors argue that endocan could be considered a suitable biological parameter for the detection of sepsisrelated deaths in forensic pathology routine [112].

Neopterin (D-erytro-1', $2^{\prime}, 3^{\prime}$-trihydroxypropylterin), a biochemical product of guanosine triphosphate pathway, has been proposed to aid in the diagnosis of bacterial [113] and viral infections [114]. Also in the forensic literature neopterin has been proposed as a marker of inflammatory diseases [115-117]. Postmortem serum neopterin levels over $500 \mathrm{nmol} / \mathrm{L}$ were observed in bacterial and viral infection cases as well as in delayed deaths due to trauma [118]. For this reason, the specificity of neopterin as a clinical marker of bacterial sepsis is limited [119].

Conclusively, there is a strong body of evidence that postmortem concentration of serum cytokines and other mediators of inflammation may be an area of great interest with exciting diagnostic possibilities for sepsis/septic shockrelated deaths $[118,119]$. However, at present, an ideal clinical and postmortem marker of sepsis does not exist [118].

In a previous review, Pierrakos and Vincent identified nearly 180 distinct molecules that have been proposed as potential biological markers of sepsis [83]. However, only $20 \%$ of these biomarkers have been assessed specifically in appropriate studies for use in the diagnosis of sepsis [84].

\section{Conclusion}

The difficulties of the postmortem diagnosis of death due to sepsis are well known. The major limitation is the poor specificity of macroscopic and routine histological findings encountered in such cases. Due to the complex molecular and cellular mechanisms underlying sepsis, proof of the presence of germs alone cannot be of evidential value in establishing a causal relationship between infection and outcome. Thus, the old saying by William Osler (1849 to 1919) "except on few occasions, the patient appears to die from the body's response to infection rather than from the infection" is still true [84].

A complete methodological approach, integrating clinical data by means of autopsy and histological and laboratory findings aiming to identify and demonstrate the host response to infectious insult, is mandatory. Such an approach would be likely to produce an accurate objective surveillance of deaths due to sepsis and improve our knowledge of the clinical-pathological correlation in sepsis, thus contributing to the evaluation of the effectiveness of therapies. Finally, autopsy is a critical tool for protection from false liability claims and settling valid claims quickly and fairly.

\section{Disclosure}

Readers can refer to Sepulchretum Sive Anatomia Practica ex Cadaveribus Morbo Denatis (Burial vault/cemetery or anatomical studies on bodies affected by disease) Bonet $\mathrm{T}$ (1679), Leonardus Chouet, Geneva.

\section{Competing Interests}

The authors declare that they have no competing interests. 


\section{References}

[1] C. Rhee, S. Gohil, and M. Klompas, "Regulatory mandates for sepsis care-reasons for caution," The New England Journal of Medicine, vol. 370, no. 18, pp. 1673-1676, 2014.

[2] S. L. Murphy, J. Xu, and K. D. Kochanek, "Deaths: preliminary data for 2010," National Vital Statistics Reports, vol. 60, no. 4, pp. $1-51,2012$.

[3] C. M. Torio and R. M. Andrews, National Inpatient Hospital Costs: The Most Expensive Conditions by Payer, 2011: Statistical Brief \#160, Healthcare Cost and Utilization Project (HCUP) Statistical Briefs, Agency for Health Care Policy and Research, 2006-2013, Rockville, Md, USA, 2011.

[4] G. Clemente, A. Tuttolomondo, D. Colomba et al., "When sepsis affects the heart: a case report and literature review," World Journal of Clinical Cases, vol. 3, no. 8, pp. 743-750, 2015.

[5] M. M. Levy, A. Artigas, G. S. Phillips et al., "Outcomes of the Surviving Sepsis Campaign in intensive care units in the USA and Europe: a prospective cohort study," The Lancet Infectious Diseases, vol. 12, no. 12, pp. 919-924, 2012.

[6] F. B. Mayr, S. Yende, and D. C. Angus, "Epidemiology of severe sepsis," Virulence, vol. 5, no. 1, pp. 4-11, 2014.

[7] C. W. Seymour, V. X. Liu, T. J. Iwashyna et al., "Assessment of clinical criteria for sepsis for the third international consensus definitions for sepsis and septic shock (Sepsis-3)," The Journal of the American Medical Association, vol. 315, no. 8, pp. 762-774, 2016.

[8] M. Shankar-Hari, G. S. Phillips, M. L. Levy et al., "Developing a new definition and assessing new clinical criteria for septic shock," The Journal of the American Medical Association, vol. 315, no. 8, pp. 775-787, 2016.

[9] S. Lucas, "Sepsis definitions," The Lancet, vol. 381, no. 9885, article 2249, 2013.

[10] S. Lucas, "The autopsy pathology of sepsis-related death," Current Diagnostic Pathology, vol. 13, no. 5, pp. 375-388, 2007.

[11] M. Tsokos, "Postmortem diagnosis of sepsis," Forensic Science International, vol. 165, no. 2-3, pp. 155-164, 2007.

[12] J. A. Morris, L. M. Harrison, and S. M. Partridge, "Postmortem bacteriology: a re-evaluation," Journal of Clinical Pathology, vol. 59, no. 1, pp. 1-9, 2006.

[13] S. A. Blosser, H. E. Zimmerman, and J. L. Stauffer, "Do autopsies of critically ill patients reveal important findings that were clinically undetected?" Critical Care Medicine, vol. 26, no. 8, pp. 1332-1336, 1998.

[14] G. D. Perkins, D. F. McAuley, S. Davies, and F. Gao, "Discrepancies between clinical and postmortem diagnoses in critically ill patients: an observational study," Critical Care, vol. 7, no. 6, pp. R129-R132, 2003.

[15] J. Roulson, E. W. Benbow, and P. S. Hasleton, "Discrepancies between clinical and autopsy diagnosis and the value of post mortem histology; a meta-analysis and review," Histopathology, vol. 47, no. 6, pp. 551-559, 2005.

[16] G. Y. A. De Vlieger, E. M. J. L. Mahieu, and W. Meersseman, "Clinical review: what is the role for autopsy in the ICU?" Critical Care, vol. 14, no. 2, article 221, 2010.

[17] C. C. H. J. Kuijpers, J. Fronczek, F. R. W. Van De Goot, H. W. M. Niessen, P. J. van Diest, and M. Jiwa, "The value of autopsies in the era of high-tech medicine: discrepant findings persist," Journal of Clinical Pathology, vol. 67, no. 6, pp. 512-519, 2014.

[18] J. G. van den Tweel and C. Wittekind, “The medical autopsy as quality assurance tool in clinical medicine: dreams and realities," Virchows Archiv, vol. 465, no. 1, pp. 75-81, 2016.
[19] S. D. Goldenberg, H. Volpé, and G. L. French, "Clinical negligence, litigation and healthcare-associated infections," Journal of Hospital Infection, vol. 81, no. 3, pp. 156-162, 2012.

[20] J. C. Marshall and K. Reinhart, "International sepsis forum. Biomarkers of sepsis," Critical Care, vol. 37, pp. 2290-2298, 2009.

[21] W. Schulte, J. Bernhagen, and R. Bucala, "Cytokines in sepsis: potent immunoregulators and potential therapeutic targets-an updated view," Mediators of Inflammation, vol. 2013, Article ID 165974, 16 pages, 2013.

[22] M. Aziz, A. Jacob, W.-L. Yang, A. Matsuda, and P. Wang, "Current trends in inflammatory and immunomodulatory mediators in sepsis," Journal of Leukocyte Biology, vol. 93, no. 3, pp. 329-342, 2013.

[23] J. Scheller, A. Chalaris, D. Schmidt-Arras, and S. Rose-John, "The pro- and anti-inflammatory properties of the cytokine interleukin-6," Biochimica et Biophysica Acta (BBA)-Molecular Cell Research, vol. 1813, no. 5, pp. 878-888, 2011.

[24] H. Chaudhry, J. Zhou, Y. Zhong et al., "Role of cytokines as a double-edged sword in sepsis," In Vivo, vol. 27, no. 6, pp. 669684, 2013.

[25] A. Ashare, L. S. Powers, N. S. Butler, K. C. Doerschug, M. M. Monick, and G. W. Hunninghake, "Anti-inflammatory response is associated with mortality and severity of infection in sepsis," American Journal of Physiology - Lung Cellular and Molecular Physiology, vol. 288, no. 4, pp. L633-L640, 2005.

[26] J. Cohen, “The immunopathogenesis of sepsis," Nature, vol. 420, no. 6917, pp. 885-891, 2002.

[27] K. Ley, C. Laudanna, M. I. Cybulsky, and S. Nourshargh, "Getting to the site of inflammation: the leukocyte adhesion cascade updated," Nature Reviews Immunology, vol. 7, no. 9, pp. 678-689, 2007.

[28] T. A. Springer, "Traffic signals for lymphocyte recirculation and leukocyte emigration: the multistep paradigm," Cell, vol. 76, no. 2, pp. 301-314, 1994.

[29] H. F. Langer and T. Chavakis, "Leukocyte-endothelial interactions in inflammation," Journal of Cellular and Molecular Medicine, vol. 13, no. 7, pp. 1211-1220, 2009.

[30] A. K. Kakkar and D. J. Lefer, "Leukocyte and endothelial adhesion molecule studies in knockout mice," Current Opinion in Pharmacology, vol. 4, no. 2, pp. 154-158, 2004.

[31] K. Xing, S. Murthy, W. C. Liles, and J. M. Singh, "Clinical utility of biomarkers of endothelial activation in sepsis-a systematic review," Critical Care, vol. 16, article R7, 2012.

[32] S. Skibsted, A. E. Jones, M. A. Puskarich et al., "Biomarkers of endothelial cell activation in early sepsis," Shock, vol. 39, no. 5, pp. 427-432, 2013.

[33] P. A. Ward, "Role of the complement in experimental sepsis," Journal of Leukocyte Biology, vol. 83, no. 3, pp. 467-470, 2008.

[34] M.-J. Rabiet, E. Huet, and F. Boulay, "The N-formyl peptide receptors and the anaphylatoxin C5a receptors: an overview," Biochimie, vol. 89, no. 9, pp. 1089-1106, 2007.

[35] P. A. Ward, "The harmful Role of C5a on innate immunity in sepsis," Journal of Innate Immunity, vol. 2, no. 5, pp. 439-445, 2010.

[36] D. Rittirsch, M. A. Flierl, B. A. Nadeau et al., "Functional roles for C5a receptors in sepsis," Nature Medicine, vol. 14, no. 5, pp. 551-557, 2008.

[37] B. J. Czermak, V. Sarma, C. L. Pierson et al., "Protective effects of C5a blockade in sepsis," Nature Medicine, vol. 5, no. 7, pp. 788792, 1999. 
[38] P. A. Ward, R.-F. Guo, and N. C. Riedemann, "Manipulation of the complement system for benefit in sepsis," Critical Care Research and Practice, vol. 2012, Article ID 427607, 8 pages, 2012.

[39] D. Rittirsch, M. A. Flierl, and P. A. Ward, "Harmful molecular mechanisms in sepsis," Nature Reviews Immunology, vol. 8, no. 10, pp. 776-787, 2008.

[40] J.-M. Cavaillon and D. Annane, "Compartmentalization of the inflammatory response in sepsis and SIRS," Journal of Endotoxin Research, vol. 12, no. 3, pp. 151-170, 2006.

[41] A. M. Chinnaiyan, M. Huber-Lang, C. Kumar-Sinha et al., "Molecular signatures of sepsis: multiorgan gene expression profiles of systemic inflammation," American Journal of Pathology, vol. 159, no. 4, pp. 1199-1209, 2001.

[42] M. A. Mercer-Jones, M. S. Shrotri, J. C. Peyton, D. G. Remick, and W. G. Cheadle, "Neutrophil sequestration in liver and lung is differentially regulated by $\mathrm{C}-\mathrm{X}-\mathrm{C}$ chemokines during experimental peritonitis," Inflammation, vol. 23, no. 4, pp. 305319, 1999.

[43] M. A. Koay, J. W. Christman, L. J. Wudel et al., "Modulation of endotoxin-induced NF- $\kappa \mathrm{B}$ activation in lung and liver through TNF type 1 and IL-1 receptors," American Journal of Physiology-Lung Cellular and Molecular Physiology, vol. 283, no. 6, pp. L1247-L1254, 2002.

[44] L. Salez, M. Singer, V. Balloy, C. Creminon, and M. Chignard, "Lack of IL-10 synthesis by murine alveolar macrophages upon lipopolysaccharide exposure. Comparison with peritoneal macrophages," Journal of Leukocyte Biology, vol. 67, no. 4, pp. 545-552, 2000.

[45] K. Suzuki, T. Suda, T. Naito, K. Ide, K. Chida, and H. Nakamura, "Impaired Toll-like receptor 9 expression in alveolar macrophages with no sensitivity to CpG DNA," American Journal of Respiratory and Critical Care Medicine, vol. 171, no. 7, pp. 707-713, 2005.

[46] A. Punturieri, R. S. Alviani, T. Polak, P. Copper, J. Sonstein, and J. L. Curtis, "Specific engagement of TLR4 or TLR3 does not lead to IFN- $\beta$-mediated innate signal amplification and STAT1 phosphorylation in resident murine alveolar macrophages," The Journal of Immunology, vol. 173, no. 2, pp. 1033-1042, 2004.

[47] B. Schrag, K. Iglesias, P. Mangin, and C. Palmiere, "Procalcitonin and C-reactive protein in pericardial fluid for postmortem diagnosis of sepsis," International Journal of Legal Medicine, vol. 126, no. 4, pp. 567-572, 2012.

[48] Å. Vege, T. O. Rognum, A. O. Aasen, and O. D. Saugstad, "Are elevated cerebrospinal fluid levels of IL-6 in sudden unexplained deaths, infectious deaths and deaths due to heart/lung disease in infants and children due to hypoxia?" Acta Paediatrica, vol. 87, no. 8, pp. 819-824, 1998.

[49] P. E. Spronk, D. F. Zandstra, and C. Ince, "Bench-to-bedside review: sepsis is a disease of the microcirculation," Critical Care, vol. 8, no. 6, pp. 462-468, 2004.

[50] A. M. Muller and M. Tsokos, "Pathology of human endothelium in septic organ failure," in Forensic Pathology Reviews, M. Tsokos, Ed., vol. 4, pp. 161-192, Humana Press, New Jersey, NJ, USA, 2006.

[51] B. Vallet, "Bench-to-bedside review: endothelial cell dysfunction in severe sepsis: a role in organ dysfunction?" Critical Care, vol. 7, no. 2, pp. 130-138, 2003.

[52] K. Reinhart, O. Bayer, F. Brunkhorst, and M. Meisner, "Markers of endothelial damage in organ dysfunction and sepsis," Critical Care Medicine, vol. 30, no. 5, pp. S302-S312, 2002.

[53] S. E. Gill, R. Taneja, M. Rohan, L. Wang, and S. Mehta, "Pulmonary microvascular albumin leak is associated with endothelial cell death in murine sepsis-induced lung injury in vivo," PLoS ONE, vol. 9, no. 2, Article ID e88501, 2014.

[54] L. Wang, R. Taneja, H. M. Razavi, C. Law, C. Gillis, and S. Mehta, "Specific role of neutrophil inducible nitric oxide synthase in murine sepsis-induced lung injury in vivo," Shock, vol. 37, no. 5, pp. 539-547, 2012.

[55] L. Wan, S. M. Bagshaw, C. Langenberg, T. Saotome, C. May, and R. Bellomo, "Pathophysiology of septic acute kidney injury: what do we really know?" Critical Care Medicine, vol. 36, no. 4, pp. S198-S203, 2008.

[56] R. Bellomo, L. Wan, C. Langenberg et al., "Septic acute kidney injury: new concepts," Nephron Experimental Nephrology, vol. 109, no. 4, pp. e95-e100, 2008.

[57] K. Ishikawa, C. N. May, G. Gobe, C. Langenberg, and R. Bellomo, "Pathophysiology of septic acute kidney injury: a different view of tubular injury," Contributions to Nephrology, vol. 165, pp. 18-27, 2010.

[58] X. Wu, R. Guo, Y. Wang, and P. N. Cunningham, "The role of ICAM-1 in endotoxin-induced acute renal failure," American Journal of Physiology-Renal Physiology, vol. 293, no. 4, pp. F1262-F1271, 2007.

[59] N. K. Patil, N. Parajuli, L. A. MacMillan-Crow, and P. R. Mayeux, "Inactivation of renal mitochondrial respiratory complexes and manganese superoxide dismutase during sepsis: mitochondriatargeted antioxidant mitigates injury," American Journal of Physiology-Renal Physiology, vol. 306, no. 7, pp. F734-F743, 2014.

[60] J. H. Holthoff, Z. Wang, K. A. Seely, N. Gokden, and P. R. Mayeux, "Resveratrol improves renal microcirculation, protects the tubular epithelium, and prolongs survival in a mouse model of sepsis-induced acute kidney injury," Kidney International, vol. 81, no. 4, pp. 370-378, 2012.

[61] Z. Wang, J. H. Holthoff, K. A. Seely et al., "Development of oxidative stress in the peritubular capillary microenvironment mediates sepsis-induced renal microcirculatory failure and acute kidney injury," American Journal of Pathology, vol. 180, no. 2, pp. 505-516, 2012.

[62] L. Wu, N. Gokden, and P. R. Mayeux, "Evidence for the role of reactive nitrogen species in polymicrobial sepsis-induced renal peritubular capillary dysfunction and tubular injury," Journal of the American Society of Nephrology, vol. 18, no. 6, pp. 1807-1815, 2007.

[63] F. S. Taccone, F. Su, C. Pierrakos et al., "Cerebral microcirculation is impaired during sepsis: an experimental study," Critical Care, vol. 14, article R140, 2010.

[64] F. S. Taccone, S. Scolletta, F. Franchi, K. Donadello, and M. Oddo, "Brain perfusion in sepsis," Current Vascular Pharmacology, vol. 11, no. 2, pp. 170-186, 2013.

[65] K. M. Omari and K. Dorovini-Zis, "CD40 expressed by human brain endothelial cells regulates $\mathrm{CD} 4+\mathrm{T}$ cell adhesion to endothelium," Journal of Neuroimmunology, vol. 134, no. 1-2, pp. 166-178, 2003.

[66] D. Wong and K. Dorovini-Zis, "Expression of vascular cell adhesion molecule-1 (VCAM-1) by human brain microvessel endothelial cells in primary culture," Microvascular Research, vol. 49, no. 3, pp. 325-339, 1995.

[67] D. C. Hess, Y. Thompson, A. Sprinkle, J. Carroll, and J. Smith, "E-selectin expression on human brain microvascular endothelial cells," Neuroscience Letters, vol. 213, no. 1, pp. 37-40, 1996.

[68] P. Rieckmanna, U. Michel, M. Albrecht, W. Bück, L. Wöckel, and K. Felgenhauer, "Cerebral endothelial cells are a major source 
for soluble intercellular adhesion molecule-1 in the human central nervous system," Neuroscience Letters, vol. 186, no. 1, pp. 61-64, 1995.

[69] D. C. Hess, T. Bhutwala, J. C. Sheppard, W. Zhao, and J. Smith, "ICAM-1 expression on human brain microvascular endothelial cells," Neuroscience Letters, vol. 168, no. 1-2, pp. 201-204, 1994.

[70] F. Meziani, X. Delabranche, P. Asfar, and F. Toti, "Bench-tobedside review: circulating microparticles-a new player in sepsis?" Critical Care, vol. 14, article 236, 2010.

[71] O. Morel, F. Toti, B. Hugel, and J.-M. Freyssinet, "Cellular microparticles: a disseminated storage pool of bioactive vascular effectors," Current Opinion in Hematology, vol. 11, no. 3, pp. 156-164, 2004.

[72] T. N. Pitanga, L. de Aragão, V. C. França et al., "Neutrophilderived microparticles induce myeloperoxidase-mediated damage of vascular endothelial cells," BMC Cell Biology, vol. 15, article 15, 2014.

[73] X. Delabranche, J. Boisramé-Helms, P. Asfar et al., "Microparticles are new biomarkers of septic shock-induced disseminated intravascular coagulopathy," Intensive Care Medicine, vol. 39, no. 10, pp. 1695-1703, 2013.

[74] V. L. Reid and N. R. Webster, "Role of microparticles in sepsis," British Journal of Anaesthesia, vol. 109, no. 4, pp. 503-513, 2012.

[75] W. Jy, L. L. Horstman, J. J. Jimenez et al., "Measuring circulating cell-derived microparticles," Journal of Thrombosis and Haemostasis, vol. 2, no. 10, pp. 1842-1851, 2004.

[76] J.-M. Freyssinet and F. Dignat-George, "More on: measuring circulating cell-derived microparticles," Journal of Thrombosis and Haemostasis, vol. 3, no. 3, pp. 613-614, 2005.

[77] M. Tokés-Füzesi, G. Woth, B. Ernyey et al., "Microparticles and acute renal dysfunction in septic patients," Journal of Critical Care, vol. 28, no. 2, pp. 141-147, 2013.

[78] G. Woth, M. Tőkés-Füzesi, T. Magyarlaki, G. L. Kovács, I. Vermes, and D. Mühl, "Activated platelet-derived microparticle numbers are elevated in patients with severe fungal (Candida albicans) sepsis," Annals of Clinical Biochemistry, vol. 49, no. 6, pp. 554-560, 2012.

[79] P. S. Prakash, C. C. Caldwell, A. B. Lentsch, T. A. Pritts, and B. R. H. Robinson, "Human microparticles generated during sepsis in patients with critical illness are neutrophil-derived and modulate the immune response," The Journal of Trauma and Acute Care Surgery, vol. 73, no. 2, pp. 401-407, 2012.

[80] C. I. Timár, Á. M. Lorincz, R. Csépányi-Kömi et al., "Antibacterial effect of microvesicles released from human neutrophilic granulocytes," Blood, vol. 121, no. 3, pp. 510-518, 2013.

[81] P. Lacy, "A new way of trapping bugs: neutrophil microvesicles," Blood, vol. 121, no. 3, pp. 420-421, 2013.

[82] J.-L. Vincent and L. Teixeira, "Sepsis biomarkers. Value and limitations," American Journal of Respiratory and Critical Care Medicine, vol. 190, no. 10, pp. 1081-1082, 2014.

[83] C. Pierrakos and J.-L. Vincent, "Sepsis biomarkers: a review," Critical Care, vol. 14, article R15, 2010.

[84] K. Reinhart, M. Bauer, N. C. Riedemann, and C. S. Hartog, "New approaches to sepsis: molecular diagnostics and biomarkers," Clinical Microbiology Reviews, vol. 25, no. 4, pp. 609-634, 2012.

[85] B. Cai, E. A. Deitch, and L. Ulloa, "Novel insights for systemic inflammation in sepsis and hemorrhage," Mediators of Inflammation, vol. 2010, Article ID 642462, 10 pages, 2010.
[86] R. A. Claus, G. P. Otto, H.-P. Deigner, and M. Bauer, "Approaching clinical reality: markers for monitoring systemic inflammation and sepsis," Current Molecular Medicine, vol. 10, no. 2, pp. 227-235, 2010.

[87] N. Tziolos, A. Kotanidou, and S. E. Orfanos, "Biomarkers in infection and sepsis: can they really indicate final outcome?" International Journal of Antimicrobial Agents, vol. 46, pp. S29S32, 2015.

[88] C. Palmiere, D. Bardy, P. Mangin, and M. Augsburger, "Value of sTREM-1, procalcitonin and CRP as laboratory parameters for postmortem diagnosis of sepsis," Journal of Infection, vol. 67, no. 6, pp. 545-555, 2013.

[89] S. Bode-Jänisch, S. Schütz, A. Schmidt et al., "Serum procalcitonin levels in the postmortem diagnosis of sepsis," Forensic Science International, vol. 226, no. 1-3, pp. 266-272, 2013.

[90] F. Ramsthaler, M. Kettner, G. Mall, and H. Bratzke, "The use of rapid diagnostic test of procalcitonin serum levels for the postmortem diagnosis of sepsis," Forensic Science International, vol. 178, no. 2-3, pp. 139-145, 2008.

[91] M. Tsokos, U. Reichelt, A. Nierhaus, and K. Püschel, "Serum procalcitonin (PCT): a valuable biochemical parameter for the post-mortem diagnosis of sepsis," International Journal of Legal Medicine, vol. 114, no. 4-5, pp. 237-243, 2001.

[92] M. Augsburger, K. Iglesias, D. Bardy, P. Mangin, and C. Palmiere, "Diagnostic value of lipopolysaccharide-binding protein and procalcitonin for sepsis diagnosis in forensic pathology," International Journal of Legal Medicine, vol. 127, no. 2, pp. 427-435, 2013.

[93] H. H. Liu, J. B. Guo, Y. Geng, and L. Su, "Procalcitonin: present and future," Irish Journal of Medical Science, vol. 184, no. 3, pp. 597-605, 2015.

[94] M. M. Shaikh, L. E. Hermans, and J. M. van Laar, "Is serum procalcitonin measurement a useful addition to a rheumatologist's repertoire? A review of its diagnostic role in systemic inflammatory diseases and joint infections," Rheumatology, vol. 54, no. 2, Article ID keu416, pp. 231-240, 2015.

[95] O. K. Eberhard, M. Haubitz, F. M. Brunkhorst, V. Kliem, K. M. Koch, and R. Brunkhorst, "Usefulness of procalcitonin for differentiation between activity of systemic autoimmune disease (systemic lupus erythematosus/systemic antineutrophil cytoplasmic antibody-associated vasculitis) and invasive bacterial infection," Arthritis \& Rheumatism, vol. 40, no. 7, pp. 12501256, 1997.

[96] B. Lindahl, H. Toss, A. Siegbahn, P. Venge, and L. Wallentin, "Markers of myocardial damage and inflammation in relation to long-term mortality in unstable coronary artery disease," The New England Journal of Medicine, vol. 343, no. 16, pp. 1139-1147, 2000.

[97] S. N. Murat, A. Kurtul, I. E. Celik et al., "The association of serum procalcitonin level with the no-reflow phenomenon after a primary percutaneous coronary intervention in patients with ST-elevation myocardial infarction," Coronary and Artery Disease, vol. 27, pp. 116-121, 2016.

[98] C. Picariello, C. Lazzeri, P. Attanà, M. Chiostri, G. F. Gensini, and S. Valente, "Procalcitonin as a reliable biomarker in acute coronary syndromes: what is its role?" Journal of Emergency Medicine, vol. 45, no. 6, pp. 921-922, 2013.

[99] A. Canbay, O. O. Celebi, S. Celebi, S. Aydogdu, and E. Diker, "Procalcitonin: a marker of heart failure," Acta Cardiologica, vol. 70, no. 4, pp. 473-478, 2015.

[100] H.-S. Tong, Y.-S. Liu, Q. Wen, Y.-Q. Tang, F.-F. Yuan, and L. $\mathrm{Su}$, "Serum procalcitonin predicting mortality in exertional 
heatstroke," Emergency Medicine Journal, vol. 29, no. 2, pp. 113117, 2012.

[101] D. Tian, S. Zhang, X. He, and H. Liu, "Serum procalcitonin as a diagnostic marker in acute ischemic stroke," NeuroReport, vol. 26, no. 1, pp. 33-37, 2015.

[102] C. Balci, R. Sivaci, G. Akbulut, and H. S. Karabekir, "Procalcitonin levels as an early marker in patients with multiple trauma under intensive care," Journal of International Medical Research, vol. 37, no. 6, pp. 1709-1717, 2009.

[103] M. Maier, S. Wutzler, M. Lehnert et al., "Serum procalcitonin levels in patients with multiple injuries including visceral trauma," Journal of Trauma-Injury, Infection and Critical Care, vol. 66, no. 1, pp. 243-249, 2009.

[104] U. Reichelt, R. Jung, A. Nierhaus, and M. Tsokos, "Serial monitoring of interleukin-1 $\beta$, soluble interleukin-2 receptor and lipopolysaccharide binding protein levels after death: a comparative evaluation of potential postmortem markers of sepsis," International Journal of Legal Medicine, vol. 119, no. 2, pp. 80-87, 2005.

[105] M. Tsokos, U. Reichelt, R. Jung, A. Nierhaus, and K. Püschel, "Interleukin-6 and C-reactive protein serum levels in sepsisrelated fatalities during the early postmortem period," Forensic Science International, vol. 119, no. 1, pp. 47-56, 2001.

[106] S. Gibot, M.-N. Kolopp-Sarda, M. C. Béné et al., "Plasma level of a triggering receptor expressed on myeloid cells-1: its diagnostic accuracy in patients with suspected sepsis," Annals of Internal Medicine, vol. 141, no. 1, pp. 9-15, 2004.

[107] L. Su, B. Han, C. Liu et al., "Value of soluble TREM-1, procalcitonin, and C-reactive protein serum levels as biomarkers for detecting bacteremia among sepsis patients with new fever in intensive care units: a prospective cohort study," BMC Infectious Diseases, vol. 12, article 157, 2012.

[108] T. Shozushima, G. Takahashi, N. Matsumoto, M. Kojika, Y. Okamura, and S. Endo, "Usefulness of presepsin (sCD14-ST) measurements as a marker for the diagnosis and severity of sepsis that satisfied diagnostic criteria of systemic inflammatory response syndrome," Journal of Infection and Chemotherapy, vol. 17, no. 6, pp. 764-769, 2011.

[109] S. Masson, P. Caironi, E. Spanuth et al., "Presepsin (soluble CD14 subtype) and procalcitonin levels for mortality prediction in sepsis: data from the Albumin Italian Outcome Sepsis trial," Critical Care, vol. 18, no. 1, article R6, 2014.

[110] C. Palmiere, M. Mussap, D. Bardy, F. Cibecchini, and P. Mangin, "Diagnostic value of soluble CD14 subtype (sCD14ST) presepsin for the postmortem diagnosis of sepsis-related fatalities," International Journal of Legal Medicine, vol. 127, no. 4, pp. 799-808, 2013.

[111] A. Scherpereel, F. Depontieu, B. Grigoriu et al., "Endocan, a new endothelial marker in human sepsis," Critical Care Medicine, vol. 34, no. 2, pp. 532-537, 2006.

[112] C. Palmiere and M. Augsburger, "Endocan measurement for the postmortem diagnosis of sepsis," Legal Medicine, vol. 16, no. 1, pp. 1-7, 2014.

[113] B. Pourakbari, S. Mamishi, J. Zafari et al., "Evaluation of procalcitonin and neopterin level in serum of patients with acute bacterial infection," The Brazilian Journal of Infectious Diseases, vol. 14, no. 3, pp. 252-255, 2010.

[114] C. Mitaka, "Clinical laboratory differentiation of infectious versus non-infectious systemic inflammatory response syndrome," Clinica Chimica Acta, vol. 351, no. 1-2, pp. 17-29, 2005.
[115] T. Ishikawa, M. Hamel, B.-L. Zhu et al., "Comparative evaluation of postmortem serum concentrations of neopterin and Creactive protein," Forensic Science International, vol. 179, no. 2-3, pp. 135-143, 2008.

[116] E. Ambach, W. Tributsch, D. Fuchs, G. Reibnegger, R. Henn, and $\mathrm{H}$. Wachter, "Postmortem evaluation of serum and urine neopterin concentrations," Journal of Forensic Sciences, vol. 36, no. 4, pp. 1089-1093, 1991.

[117] E. Ambach, W. Tributsch, W. Rabl et al., "Postmortem neopterin concentrations: comparison of diagnoses with and without cellular immunological background," International Journal of Legal Medicine, vol. 104, no. 5, pp. 259-262, 1991.

[118] C. Palmiere and M. Augsburger, "Markers for sepsis diagnosis in the forensic setting: state of the art," Croatian Medical Journal, vol. 55, no. 2, pp. 103-114, 2014.

[119] S. De Rosa, P. Cirillo, M. Pacileo et al., "Neopterin: from forgotten biomarker to leading actor in cardiovascular pathophysiology," Current Vascular Pharmacology, vol. 9, no. 2, pp. 188199, 2011. 


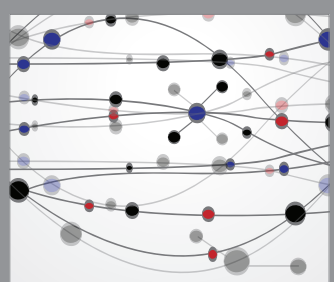

The Scientific World Journal
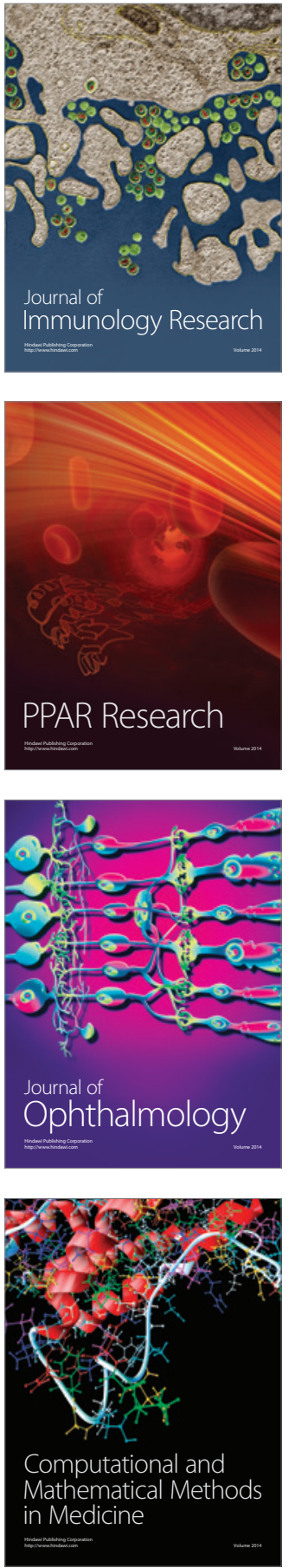

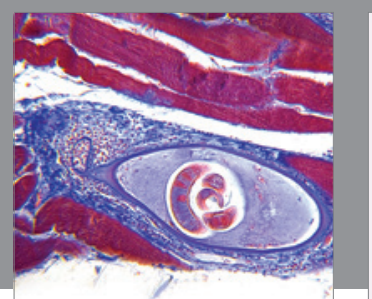

Gastroenterology Research and Practice

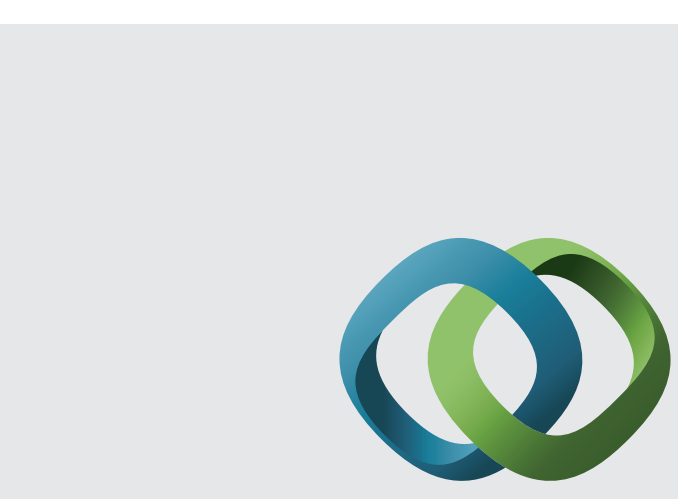

\section{Hindawi}

Submit your manuscripts at

http://www.hindawi.com
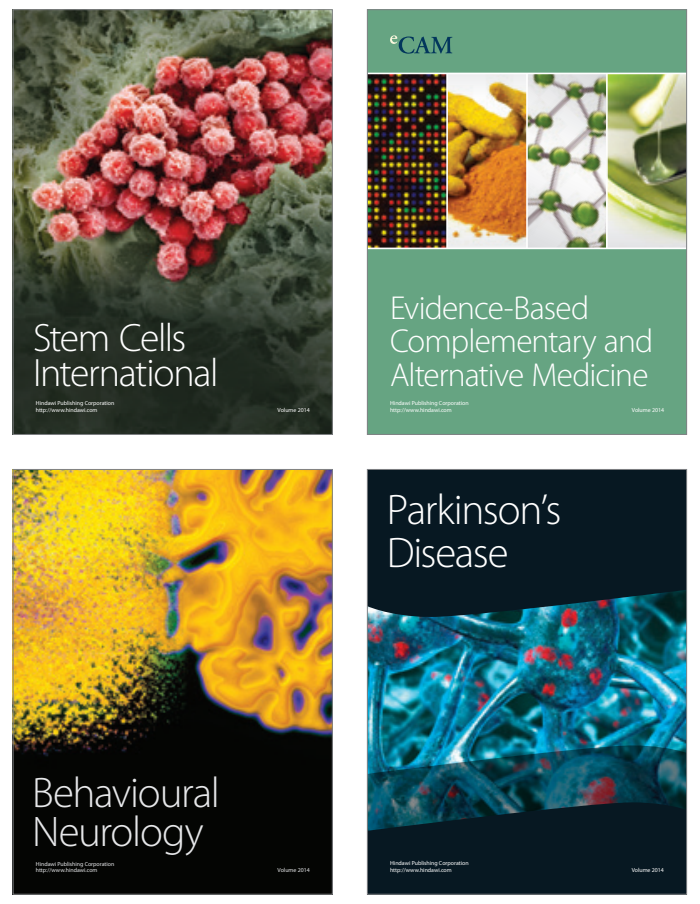
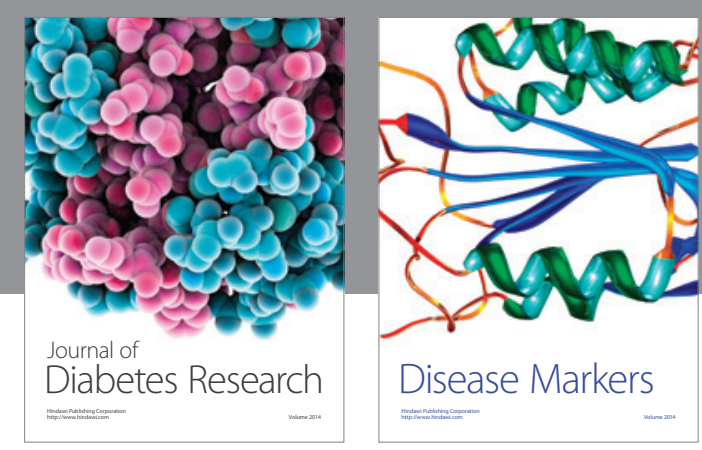

Disease Markers
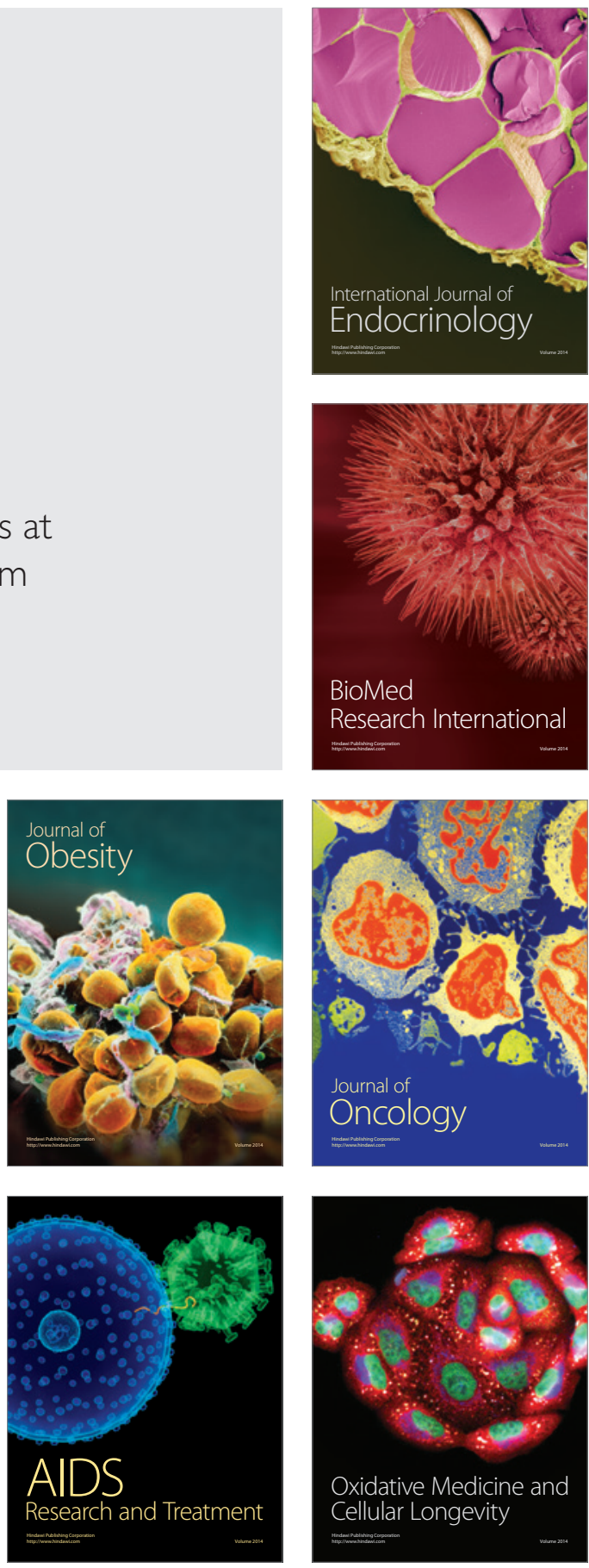